\title{
Production of Glassy Coil Springs by Warm Coiling of Zr-based Glassy Alloy Wires
}

\author{
Satoru Ishihara ${ }^{1, *}$, Hideki Soejima ${ }^{1}$, Shigeo Komaba ${ }^{2}$, Hiroyuki Takehisa ${ }^{2}$, Masakazu Shimanuki ${ }^{2}$, \\ Xin-min Wang ${ }^{3}$ and Akihisa Inoue ${ }^{4}$ \\ ${ }^{1} R \& D$ Institute of Metals and Composites for Future Industries, Sendai 980-8577, Japan \\ ${ }^{2}$ Fuji Heavy Industries Ltd., Utsunomiya 320-8564, Japan \\ ${ }^{3}$ Japan Basic Material Ltd., Sendai 982-0261, Japan \\ ${ }^{4}$ Institute for Materials Research, Tohoku University, Sendai 980-8577, Japan
}

\begin{abstract}
This study examines forming of coil springs from glassy alloy wires by warm coiling. Glassy Zr-Al-Ni-Cu alloy wires with a diameter of $1 \mathrm{~mm}$ were prepared by the rotating grooved-disk casting method and were wound round metal molds which were heated up to the supercooled liquid region of the alloy. Coil springs with mean diameters of $19 \mathrm{~mm}$ and $7.2 \mathrm{~mm}$ were formed by the warm coiling process. The coil springs formed within $1.8 \mathrm{ks}$ in a temperature range between $673 \mathrm{~K}$ and $723 \mathrm{~K}$ maintained the glassy state, while the part heated for longer time in the coil spring formed at temperatures between $693 \mathrm{~K}$ and $743 \mathrm{~K}$ was crystallized. The spring constants of the coil springs measured by compressive test agree with the respective spring constant values calculated from the dimensions of the springs and the shear modulus of the alloy.
\end{abstract}

(Received May 17, 2004; Accepted June 21, 2004)

Keywords: zirconium-aluminum-nickel-copper alloy, rotating grooved-disk casting, supercooled liquid region, viscous flow, spring constant

\section{Introduction}

Glassy alloys with a large supercooled liquid region before crystallization have been found in many multicomponent systems. ${ }^{1)} \mathrm{Zr}-\mathrm{Al}-\mathrm{Ni}-\mathrm{Cu}$ glassy alloys have especially high glass-forming ability $^{2)}$ and a large supercooled liquid region. ${ }^{3)}$ Furthermore, attractive engineering characteristics such as high mechanical strength ${ }^{4}$ and high corrosion resistance $^{5)}$ have been reported in Zr-based glassy alloys. Low Young's modulus and high elastic limit as well as high strength are known as unique mechanical properties of metallic glasses. These properties of metallic glasses are suitable for spring materials, and hence, coil springs can be one of good candidates for industrial applications of metallic glasses. Viscous flow in the supercooled liquid region has also been reported in some metallic glasses, as one of useful characteristics of glassy materials. ${ }^{6-8)}$ Such behavior is useful for shape forming and has been applied for fabrication of gears for micro electromechanical system. ${ }^{9}$ Coil springs are expected to be formed by coiling treatment of glassy alloy wires in the supercooled liquid region.

Continuous amorphous alloy wires have been fabricated by some methods such as in-rotating-water melt spinning method, ${ }^{10)}$ glass-coating spinning method (Taylor method), ${ }^{11)}$ and melt extraction method. ${ }^{12)}$ It is, however, difficult to fabricate wires with diameters over $200 \mu \mathrm{m}$ by these methods, because of morphological instability of molten metal with large diameters. Recently, a rotating grooved-disk casting method has been developed for production of continuous glassy alloy wires with diameters from 0.5 to $1.5 \mathrm{~mm} .{ }^{13)}$ This method is considered to be suitable for production of glassy alloy wires which can be used for forming of coil springs. In this study, we have tried to produce coil springs by the warm coiling treatment of glassy $\mathrm{Zr}-\mathrm{Al}-\mathrm{Ni}-\mathrm{Cu}$ alloy wires in the supercooled liquid region. This paper presents the results about the forming of coil

*Present address: National Institute for Materials Science, Tsukuba 305-0044, Japan springs and the elastic properties of the formed coil springs.

\section{Experimental Procedure}

A multi-component Zr-based alloy with a composition of $\mathrm{Zr}_{55} \mathrm{Al}_{10} \mathrm{Ni}_{5} \mathrm{Cu}_{30}$ (at\%) was examined in the present study. The alloy composition represents nominal atomic mixture. Its master alloy ingot was first prepared by arc melting the mixture of pure metals in an argon atmosphere. The alloy wires with a diameter of $1 \mathrm{~mm}$ were produced by the rotating grooved-disk casting method. The alloy ingot was melted in a quartz tube in a high-frequency induction furnace and cast into a semicircular groove on the rotating disk. The diameter of the ejection nozzle was $0.4 \mathrm{~mm}$. The coil springs were produced by forming the wires as shown in Fig. 1. The wire was wound round a metal mold which was heated at temperatures higher than the glass transition temperature of the alloy with a high-frequency induction system and rotated with a motor. Ar gas was blown for cooling of the wound wires.

The glassy and crystallized structures of the produced springs were examined by X-ray diffraction (XRD). Thermal stability associated with glass transition and crystallization was examined by differential scanning calorimetry (DSC) at a heating rate of $0.67 \mathrm{~K} / \mathrm{s}$. Compressive tests of the coil

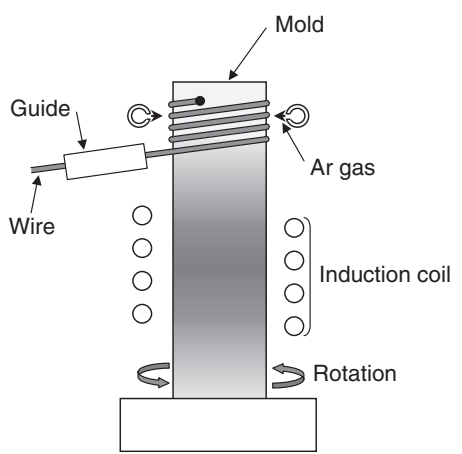

Fig. 1 Schematic illustration of the warm coiling method, in which the wire is wound round metal molds heated with a high-frequency induction system. 


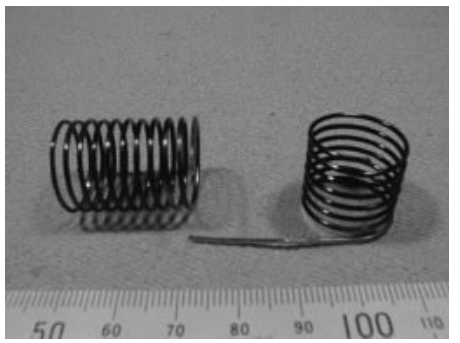

Fig. 2 Appearance of the $\mathrm{Zr}_{55} \mathrm{Al}_{10} \mathrm{Ni}_{5} \mathrm{Cu}_{30}$ glassy coil spring produced by the warm coiling method in which the wire is wound round the mold of $18 \mathrm{~mm}$ in outer diameter.

springs were conducted with an Instron type testing machine for measurement of elastic property.

\section{Results and Discussion}

Figure 2 shows an appearance of the coil spring which was produced by the winding method round the metal mold with an outer diameter of $18 \mathrm{~mm}$. The mold was heated at about $703 \mathrm{~K}$ which is $20 \mathrm{~K}$ higher than the glass transition temperature of the alloy. The temperature of this mold, however, fluctuated within 693-743 K during the winding of the wire. Figure 3 shows the XRD patterns for both the coil end parts of the coil spring. The diffraction pattern at the last part of the winding (Fig. 3-b) consists of a halo pattern, and no detectable diffraction peak of crystalline phase is seen. However, the result on the first part (Fig. 3-a) shows crystalline peaks, which are mainly identified as $\mathrm{Zr}_{2} \mathrm{Cu}$ and $\mathrm{Zr}_{2} \mathrm{Ni}$ phases. The DSC curves on both the end parts of the coil spring are shown in Fig. 4, together with the result of the glassy wire. A typical endothermic reaction due to glass transition and a distinct exothermic peak due to crystallization are observed in the DSC curve obtained from the last part of the winding (Fig. 4-b). Here, $T_{\mathrm{g}}$ is defined as the onset of the glass transition temperature and $T_{\mathrm{x}}$, the crystallization event, respective-

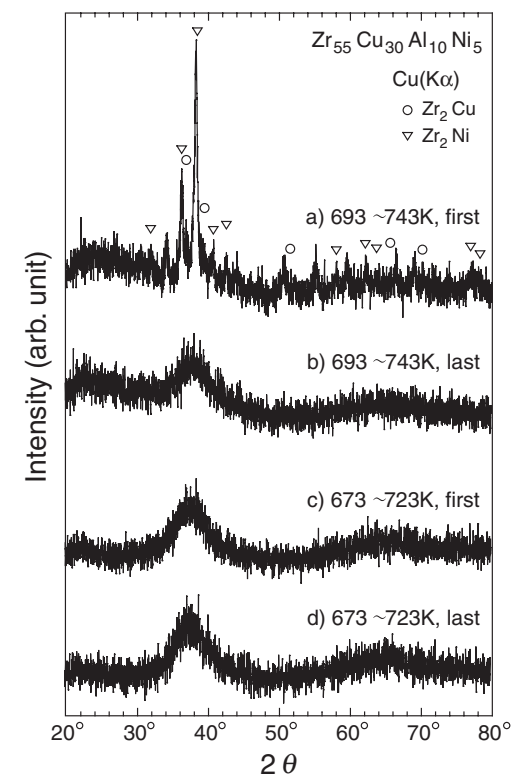

Fig. 3 X-ray diffraction patterns taken from the first (a, c) and last (b, d) parts of the wound wires. The coil springs were formed at the temperatures within 693-743 K (a, b) and 673-723 K (c, d).

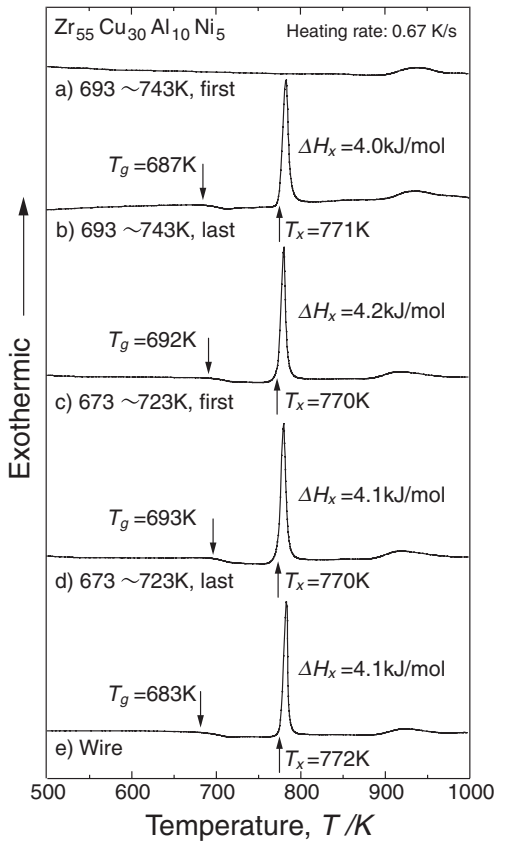

Fig. 4 DSC curves of the first $(a, c)$ and last (b, d) parts of the wound wires. The coil springs were formed at the temperatures within $693-743 \mathrm{~K}(\mathrm{a}, \mathrm{b})$ and $673-723 \mathrm{~K}(\mathrm{c}, \mathrm{d})$. The result of the glassy wire (e) is also shown for comparison.

ly. The $T_{\mathrm{g}}$ and $T_{\mathrm{x}}$ at the last part are 687 and $771 \mathrm{~K}$, respectively, in agreement with those (683 and $772 \mathrm{~K}$ ) for the glassy wire (Fig. 4-e). The heat of crystallization $\left(\Delta H_{\mathrm{x}}\right)$ of the last part is $4.0 \mathrm{~kJ} / \mathrm{mol}$ and nearly the same as that $(4.1 \mathrm{~kJ} / \mathrm{mol})$ of the glassy wire. However, neither endothermic nor exothermic reaction is observed in the DSC curve for the first part of the winding (Fig. 4-a). These XRD and DSC data indicate that the formed spring has crystallized at the first part of the winding heated for the longest time, while the last part maintains the glassy state. The crystallization at the first part is considered to be caused by the heat from the mold during the winding of the following parts, though the part has not crystallized during coiling.

Then, another experiment of coiling was tried under the heating condition where the temperature is $20 \mathrm{~K}$ lower than the previous coiling experiment. The temperature fluctuation during this winding was within $673-723 \mathrm{~K}$. The XRD patterns and DSC curves on both the coil end parts of this spring are shown in Figs. 3 and 4. The diffraction pattern at the last part of the winding (Fig. 3-d) consists of a halo pattern which is the same as that for the previous spring. The result obtained from the first part (Fig. 3-c) also shows a halo pattern for the spring formed at the lower heating condition. A typical endothermic reaction due to glass transition and a large exothermic peak due to crystallization are observed in the DSC curves obtained from the last and first parts of the winding (Figs. 4-c and -d). The $T_{\mathrm{g}}, T_{\mathrm{x}}$ and $\Delta H_{\mathrm{x}}$ are $692 \mathrm{~K}$, $770 \mathrm{~K}$ and $4.2 \mathrm{~kJ} / \mathrm{mol}$, respectively, for the last part, while $693 \mathrm{~K}, 770 \mathrm{~K}$ and $4.1 \mathrm{~kJ} / \mathrm{mol}$, respectively, for the first part. These data are also in agreement with those for the glassy wire (Fig. 4-e). These XRD and DSC data indicate that the formed spring can maintain the glassy state under appropriate heating conditions.

The coil springs with an outer diameter of $8.5 \mathrm{~mm}$ were 


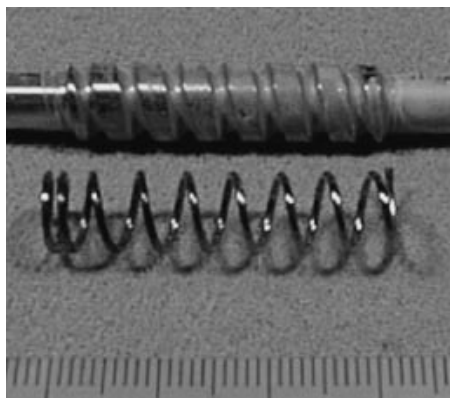

Fig. 5 Appearances of the mold and the coil spring for measurement of elastic property.

formed under the same heating condition for the measurement of elastic properties. The appearances of the mold and the coil spring formed with the mold are shown in Fig. 5. The springs have a regular pitch at the intermediate part, but the pitch is changed at the coil ends so that both the coil end faces are perpendicular to the longitudinal direction of the coil spring, as shown in Fig. 5. Three coil springs were examined for the measurement of elastic property. The relation between compressive load and displacement is shown in Fig. 6. The slope of approximately linear line of the experimental data corresponds to the spring constant of each coil spring.

The spring constant $(K)$ of the coil spring can be calculated as follows, ${ }^{14)}$

$$
K=G d^{4} / 8 N a D^{3} .
$$

Here, $D$ is the mean diameter of coil, $d$ is the wire diameter, $G$ is shear modulus, and $\mathrm{Na}$ is the number of active turns. The experimental value of shear modulus for the Zr-based glassy alloy, 33.7 GPa was used for this calculation. This value was obtained with an ultrasonic measuring system by using a cylindrical sample with a diameter of $8 \mathrm{~mm}$ and a length of $10 \mathrm{~mm}$ fabricated by casting into a copper mold. The dimensions of these coil springs and the calculated values are summarized in Table 1. The experimental values of spring constant for these coil springs obtained by the linear approximation method are also listed in Table 1 together with the calculated values. The experimental results on the spring constants of the coil springs almost agree with the respective calculated values. The agreement indicates that glassy coil springs can be formed by the present forming process and their spring constants can be calculated on the basis of the dimensions of springs and shear modulus of the alloy.

\section{Conclusions}

We have produced coil springs by warm coiling of glassy alloy wires. The glassy $\mathrm{Zr}-\mathrm{Al}-\mathrm{Ni}-\mathrm{Cu}$ alloy wire with a diameter of $1 \mathrm{~mm}$ was prepared by the rotating grooved-disk casting method and then wound round a metal mold which was heated in the supercooled liquid region. Coil springs were formed accompanying a small spring back. The coil springs maintained the glassy state in case of forming under appropriate heating conditions. The spring constants of the coil springs measured by the compressive test agree with the respective values calculated from the dimensions of the coil springs and the shear modulus of the alloy.

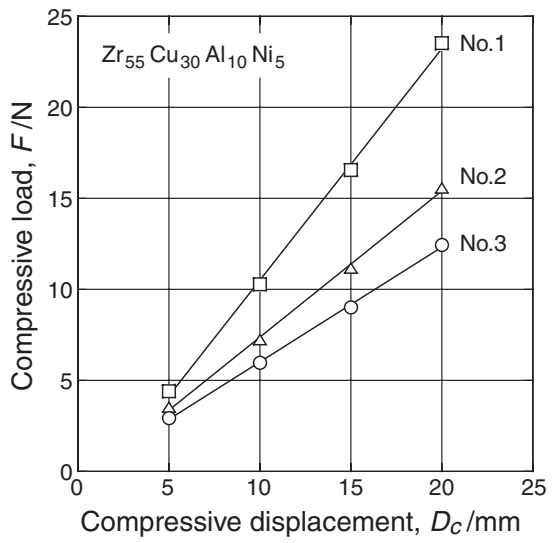

Fig. 6 Relation between compressive load and compressive displacement for the $\mathrm{Zr}_{55} \mathrm{Al}_{10} \mathrm{Ni}_{5} \mathrm{Cu}_{30}$ glassy alloy coil springs formed by the warm coiling method at the temperatures within $673-723 \mathrm{~K}$.

Table 1 Dimensions and spring constants of $\mathrm{Zr}_{55} \mathrm{Al}_{10} \mathrm{Ni}_{5} \mathrm{Cu}_{30}$ glassy coil springs.

\begin{tabular}{lccc}
\hline \multicolumn{1}{c}{ Spring } & No. 1 & No. 2 & No. 3 \\
\hline $\begin{array}{l}\text { Wire diameter: } d \\
\begin{array}{l}\text { Mean diameter of } \\
\text { coil: } D\end{array}\end{array}$ & $1.0 \mathrm{~mm}$ & $0.90 \mathrm{~mm}$ & $0.85 \mathrm{~mm}$ \\
$\begin{array}{l}\text { Spring constant: } K_{\text {cal }} \\
\text { (calculation) }\end{array}$ & $1.3 \mathrm{~mm}$ & $7.2 \mathrm{~mm}$ & $7.2 \mathrm{~mm}$ \\
$\begin{array}{l}\text { Spring constant: } K_{\text {exp }} \\
\text { (experiment) }\end{array}$ & $1.3 \mathrm{~N} / \mathrm{mm}$ & $0.80 \mathrm{~N} / \mathrm{mm}$ & $0.63 \mathrm{~N} / \mathrm{mm}$ \\
\hline
\end{tabular}

\section{Acknowledgements}

This work has been carried out under "Processing Technology for Metallic Glasses" in "Material Industrial Competitiveness Strengthening Program". The authors are grateful for financial support of "New Energy and Industrial Technology Development" (NEDO) and "Ministry of Economy, Trade and Industry" (METI).

\section{REFERENCES}

1) A. Inoue: Acta Mater. 48 (2000) 279-306.

2) A. Inoue and T. Zhang: Mater. Trans., JIM 37 (1996) 185-187.

3) T. Zhang, A. Inoue and T. Masumoto: Mater. Trans., JIM 32 (1991) 1005-1010.

4) A. Inoue, T. Zhang and T. Masumoto: Mater. Trans., JIM 36 (1995) 391-398.

5) S. Pang, T. Zhang, H. Kimura, K. Asami and A. Inoue: Mater. Trans., JIM 41 (2000) 1490-1494.

6) D. Polk and D. Turnbull: Acta Metall. 20 (1972) 493-498.

7) H. S. Chen and M. Goldstein: J. Appl. Phys. 43 (1972) 1642-1648.

8) H. Okumura, H. S. Chen, A. Inoue and T. Masumoto: J. Non-Cryst. Solids 130 (1991) 304-310.

9) Y. Saotome and A. Inoue: Proc. IEEE the 13th Annual Int. Conf. on Micro Electro Mechanical Systems 2000, (2000) 288-292.

10) T. Ohnaka, T. Fukusaki and T. Ohmichi: J. Japan. Inst. Metals 45 (1981) 751-758

11) T. Goto: Mater. Trans., JIM 21 (1980) 219-225.

12) A. Inoue, K. Amiya, I. Yoshii, H. M. Kimura and T. Masumoto: Mater. Trans., JIM 35 (1994) 485-488.

13) T. Zhang and A. Inoue: Mater. Trans., JIM 41 (2000) 1463-1466.

14) JIS B2704. 